\title{
CAPÍTULO 10 \\ OS IMPACTOS SOCIOAMBIENTAIS NO RIO MURUCUPI - PA SOB À LUZ DA POLÍTICA NACIONAL DE RECURSOS HÍDRICOS.
}

\author{
Ana Beatriz Matos Rodrigues. E-mail: anabrodriguesz@gmail.com \\ Karoliny Costa Santos. \\ 1;2 - Autora para correspondência \\ 2 - Universidade do Estado do Pará - Engenharia Ambietnal_2015_Campus VI - \\ Paragominas - PA. \\ DOI:10.4322/978-85-455202-0-7-10
}

\begin{abstract}
RESUMO
Os impactos ambientais no Rio Murucupi comprometem a qualidade da água e do solo. Partindo da perspectiva da Política Nacional dos Recursos Hídricos - PNRH, a pesquisa tem como objetivo correlacionar os impactos ambientais decorrentes do lançamento de efluentes domésticos e industriais no Rio Mucurupi - PA, com a as resoluções SO Conselho Nacional do Meio Ambiente - CONAMA, n. 357:2005 e n. 420:2009. O método aplicado na pesquisa foi o indutivo, com pesquisa qualitativa, a técnica aplicada para a obtenção de dados foi o levantamento de dados documentais em sites de livre acesso: Instituto Brasileiro de Geografia e Estatística - IBGE; duas bases de pesquisa Coordenação de Aperfeiçoamento de Pesquisa do Ensino Superior- CAPES, Scientific Eletronic Library Online - SciELO. Barcarena é um município industrial, onde três empresas realizam a atividade de beneficiamento de minério e despeja o rejeito no Rio Murucupi. Logo, essa atividade afeta a vulnerabilidade dos recursos naturais e aponta deficiências na Política Nacional dos Recursos Hídricos e em seus instrumentos.
\end{abstract}

PALAVRAS CHAVE: Barcarena. Efluentes. Legislação.

\begin{abstract}
Environmental impacts on River Murucupi undertake water quality and soil. From the perspective of National water resources Policy - PNRH, the research aims to correlate the environmental impacts arising from the launch of domestic and industrial effluents into the river Mucurupi-PA, with the only Council resolutions National environment CONAMA, n. 357:2005 and n. 420:2009. The method applied in the research was the inductive, with qualitative research, the technology used for the data collection was the documentary data on sites of free access: Brazilian Institute of geography and statisticsIBGE; two research bases - coordination of improvement of higher education researchCAPES, Scientific Electronic Library Online-SciELO. Barcarena is a town where three
\end{abstract}


companies carry out industrial activity of processing of ore and dumps the tailings in the river Murucupi. This activity affects vulnerability of natural resources and weaknesses in National water resources policy instruments.

KEY WORDS: Barcarena. Effluents. Legislation.

\section{INTRODUÇÃO}

A água é um recurso natural essencial para toda vida na terra, é indispensável para manutenção dos ciclos biológicos, geológicos e químicos colaborando para manter o equilíbrio dos ecossistemas e pode ser usada como estratégia para o desenvolvimento econômico. A Constituição da República, de 1988, considera a água um bem da União e do Estado e que o acesso é um direito humano que deve ser garantido pelo poder público (SILVA, 2016).

A qualidade da água é um aspecto decisivo, quando se trata dos seus principais usos, em especial, para fins como o abastecimento humano, contudo, as atividades antrópicas vêm comprometendo a qualidade e quantidade da água disponível para o uso humano. Todavia, houve a necessidade de se criar medidas para assegurar a proteção e o uso sustentável dos mesmos (SOUZA et al., 2014).

Neste sentido, em 1997, a Lei Federal n. 9.433:1997, instituiu a Política Nacional de Recursos Hídricos - PNRH, a qual traz, dentre seus instrumentos, o enquadramento dos corpos de água em classes, segundo os usos preponderantes da água, e critérios e valores para monitoramento de qualidade do solo quanto a presença de substâncias químicas (BRASIL, 1997).

Os documentos jurídicos complementares a essa Lei, foram emitidos pelo Conselho Nacional do Meio Ambiente - CONAMA, n. 357:2005, estabeleceu os padrões de qualidade da água, serve como instrumento para a PNRH, no qual o objetivo do enquadramento é assegurar às águas qualidade compatível com os usos mais exigentes a que forem destinadas e diminuir os custos de combate à poluição das águas, mediante a ações preventivas ao meio ambiente.

Outra resolução do mesmo Conselho, de n. 420:2009, dispõe sobre critérios e valores orientadores de qualidade do solo quanto à presença de substâncias químicas e estabelece diretrizes para o gerenciamento ambiental de áreas contaminadas por essas substâncias em decorrência de atividades resultantes da ação humana sobre a natureza.

Então, o lançamento de efluentes industriais em corpos hídricos, continua a ser ao problema, e necessita ser pesquisa com afinco, o que justifica e incrementa a relevância dessa pesquisa, cujo objetivo é correlacionar os impactos ambientais decorrentes do lançamento de efluentes industriais no Rio Mucurupi - PA, com a Política Nacional de Recursos Hídricos - PNRH, as resoluções Conama 357:2005 e 420:2009, e gerar dados que contribuam para a solução do mesmo com aplicações práticas.

\section{IMPACTOS AMBIENTAIS EM CORPOS HÍDRICOS LÓTICOS}


Os impactos ambientais em corpos hídricos consequentes do crescimento populacional associado ao aumento das atividades industriais e à expansão agrícola, foi significativo e, em áreas com elevada densidade populacional observa-se que os impactos decorrem, principalmente, do lançamento de efluentes domésticos e industriais, os quais aportam matéria orgânica, nutrientes, substâncias inorgânicas e tóxicas (BEM; BRAGA; AZEVEDO, 2013).

Portanto no município de Barcarena - PA, tem-se um polo industrial que desenvolvem atividades relacionadas a mineração, no qual geraram intensas modificações econômicas, sociais e principalmente ambientais. Consequentemente atingiu a rede de drenagem da bacia do rio Murucupi, que recebe parte de rejeito sólidos da indústria de mineração, além de ser ocupado por comunidades tradicionais e espaços urbanos (BORDALO; SILVA; SANTOS, 2012).

Nesse contexto, os impactos ambientais por meio da transformação de alumínio, são consideráveis devido à ausência de grande severidade de princípios da legislação ambiental no Brasil. Deste modo atinge diretamente as regiões tradicionais no entorno da bacia hidrográfica, a sobrevivência dos corpos d'água e impossibilita as atividades diárias de subsistência e lazer (BORDALO; FERREIRA; SILVA, 2017).

\section{EFLUENTES - CONCEITO E TIPOS}

Efluentes são os resíduos provenientes das indústrias, dos esgotos e das redes pluviais, que são lançados no meio ambiente, na forma de líquidos ou de gases. A palavra efluente significa aquele que flui. É qualquer líquido ou gás gerado nas diversas atividades humanas e que são descartados na natureza. Cada efluente possui característica própria inerente à sua procedência, podendo conter as mais variadas substâncias (BELTRAME; LHAMBY; BELTRAME, 2016).

\section{EFLUENTES INDUSTRIAIS}

São os resíduos líquidos ou os gases provenientes das indústrias e que são descartados na natureza. A composição desses efluentes varia de acordo com o ramo de atividade exercida, podendo resultar em diferentes tipos de substâncias carregadas de produtos químicos, poluentes que devem ser tratados, a maioria de indústrias e a crescente geração de efluentes e seu descarte vem cada vez mais despertando a preocupação da sociedade (FERREIRA; LIMA; LEÂO, 2011).

Desta forma os efluentes industriais são divididos em resíduos industriais orgânicos e inorgânicos, especialmente os metais pesados, estes provêm também das atividades de mineração, que ao serem despejados em corpos hídricos provoca sérios problemas ambientais e sanitários, onde compromete a integridade das bacias de drenagem dos rios em que são afetados (BAHIA et al., 2012). 


\section{PROCESSO DE REFINARIA DA BAUXITA}

O Processo Bayer (Figura 1), a bauxita é processada e é gerada a alumina. Neste processo, um resíduo altamente alcalino, lama vermelha, é gerado e seu descarte representa um grande problema ambiental. A bauxita é um minério constituído essencialmente por hidróxidos de alumínio, óxidos e hidróxidos de ferro, caulinita ou haloisita, óxido de titânio e outros elementos. É o minério mais utilizado para produção de alumina e alumínio (ANTUNES et al., 2012).

Figura 1- Fluxograma do processo Bayer

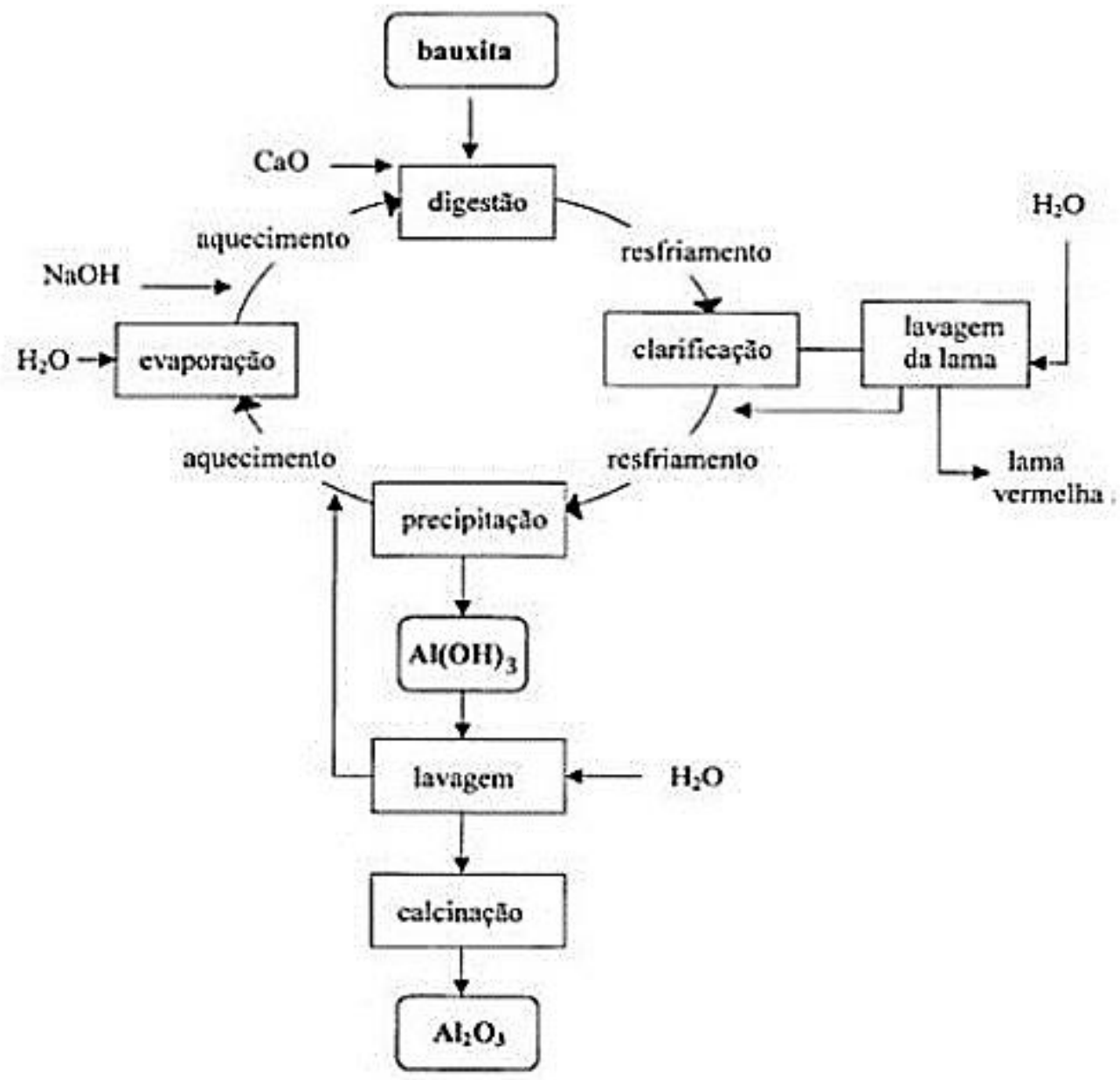

Fonte: Antunes (2012)

Por consequência, desse processo a lama vermelha gerada pode chegar ao dobro da alumina produzida, porém esta não é considerada sobretudo tóxica. Haja vista que possui uma alta alcalinidade o que pode causar grandes impactos ambientais. Com isso é necessário seu despejo em locais adequados, o que acarreta elevados custos para as indústrias de mineração, pois o armazenamento desse material requer altas técnicas de 
elevados custos, que impossibilite a contaminação dos corpos hídricos (ANTUNES; CONCEIÇÃO; NAVARRO, 2011).

\section{LEGISLAÇÃO DA GESTÃO DE RECURSOS HÍDRICOS}

A primeira lei voltada para os recursos hídricos no Brasil foi o Código das águas, pelo Decreto n. 24.643:1934, traz diretrizes em que permite o poder público controlar e incentivar o aproveitamento industrial das águas. Contudo as questões de escassez da água começaram a agravar, ocorrendo mudanças da visão dos fins de seu uso principalmente pelos governantes. Assim a Constituição de 1988, teve um papel importante alterando o domínio para a gestão desses recursos, o que determina a competência da União a criação de um Sistema Nacional de Gerenciamento de Recursos Hídricos (COUCEIRO; HAMADA, 2011).

Então em 1997, foi sancionada pelo Presidente da República a Lei de n. 9433, que instituiu a Política Nacional dos Recursos Hídricos - PNRH. A água é considerada um bem de domínio público e recurso limitado, dotado de valor econômico. Também atribui o Brasil de instrumentos legais no qual prevê o dever da gestão dos recursos hídricos em proporcionar os usos múltiplos das águas, de forma descentralizada e participativa, tanto do poder público, usuários e comunidades. Além de que o consumo humano e de animais é prioritário quando ocorrer escassez (PEREIRA; MEDEIROS, 2009).

Os instrumentos aplicados na gestão dos recursos naturais também estão definidos nas políticas de recursos hídricos. Como o enquadramento dos corpos de água, disposto pela Resolução Conama n. 357:2005, de acordo com seus usos preponderantes, e para o lançamento de efluentes. Bem como, fixou limites superiores ou inferiores para diversas variáveis como, oxigênio dissolvido, turbidez, demanda bioquímica de oxigênio, entre outras, para sistemas de água doce, salobra e salina. Do mesmo modo, o Sistema de informações de recursos hídricos tem uma grande importância quanto ao planejamento para a gestão dos recursos (CUNHA; CALIJURI, 2010).

Como também a outorga de direito de uso dos recursos hídricos, é um instrumento com o objetivo principal de assegurar o controle quantitativo e qualitativo dos corpos hídricos e o efetivo exercício do direito de acesso às águas. Por isso as diversas demandas para os usos das águas necessitam de uma autorização da autoridade competente do Poder executivo federal, dos Estados, ou Distrito Federal para poder aumentar ou diminuir vazões ou volumes de água em determinado ponto de captação no corpo hídrico, para o abastecimento doméstico, industrial ou irrigação, e modificar suas características originais (BEZERRA; MACHADO; GOMES, 2013).

Outro fator importante foi a cobrança pelo uso dos recursos hídricos, como captação e lançamento de efluentes, onde tem como objetivo principal a economia e medidas preventivas deste recurso, além de arrecadar recursos para investimentos em programas de preservação da água (AUGUSTO et al., 2012).

Portanto, os instrumentos da Política Nacional de Recursos Hídricos, são de grande importância para a melhoria das disponibilidades hídricas em quantidade e 
qualidade, a redução dos conflitos reais e potenciais de uso da água, bem como dos eventos hidrológicos críticos e a percepção da conservação da água como valor socioambiental relevante (WOLKMER; PIMMEL, 2013).

\section{METODOLOGIA}

O método aplicado foi indutivo uma vez que ele é um processo mental por meio do qual infere-se uma verdade geral ou universal, nesse caso os impactos ambientais ocasionados por ação antrópica estão contidos nos fatos examinados. Mas, para isso, parte-se de fatos particulares como o lançamento de efluentes industriais que proporcionam a descaracterização do Rio Mucurupi - PA quanto à sua qualidade, o que compromete o seu uso. Portanto, o objetivo da inferência indutiva é levar a conclusões cujo conteúdo é muito mais amplo do que as premissas nas quais foram baseadas (GIL, 2008).

Quanto à finalidade da pesquisa, ela é classificada como fundamental, com a natureza observativa, e abordagem quantiqualitativa, e procedimento exploratório, técnico bibliográfico (PRODANOV; FREITAS, 2013).

A técnica aplicada para a obtenção de dados foi o levantamento de dados documentais, cujo recorte temporal foi de 2009 a 2018, para que se tivesse acesso a informações decenais já publicadas. Para tal, utilizou-se sites de livre acesso Instituto Brasileiro de Geografia e Estatística - IBGE, bases de pesquisas como a Coordenação de Aperfeiçoamento de Pessoal de Nível Superior - CAPES e Scientific Electronic Library Online - SciELO.

\section{ÁREA DE ESTUDO}

O município de Barcarena, no Estado do Pará, conta com um polo industrial complexo para o beneficiamento da bauxita em alumínio, cujo finalidade, é a exportação, localizada próximo a nascente do rio Murucupi, o qual passa 50 metros da bacia de resíduos desse processo industrial, e está relacionada a dois fenômenos preocupantes que ocorreram no ano de 2003, a mortandade de peixes e a transbordamento da bacia de resíduos (CARMO; COSTA, 2016).

O Rio Murucupi, estende-se desde a área correspondente ao distrito industrial, transpassando pela área da Vila dos Cabanos, bairro do Laranjal, São Lourenço, Boa Vista desembocando até o furo do Arrozal. As nascentes do Rio Murucupi estão situadas às proximidades da bacia de rejeito da empresa Alunorte (IEC-SAMAN, 2009). O que caracteriza a sua fragilidade e a necessidade de políticas de gestão compartilhada por todos os atores sociais e o poder público local e estadual, dividindo responsabilidades sobre esse recurso hídrico em questão. 


\section{DISCUSSÕES}

\section{QUANTO AOS IMPACTOS SOCIOAMBIENTAIS}

Segundo informações oficiais do censo do Instituto Brasileiro de Geografia e Estatística (IBGE), em 1970, 79,12\% da população economicamente ativa estavam ligados à atividade agropecuária, ao extrativismo vegetal e à pesca, o que demonstra que a economia do município se concentrava no meio rural, onde também estava assentada a maioria da população.

No entanto, a partir da análise dos dados obtidos (Figura 2) quanto ao cadastro central de empresas no município, indicaram que a partir do ano de 2006 houve um aumento significativo do número de empresas instaladas no município (IBGE, 2015).

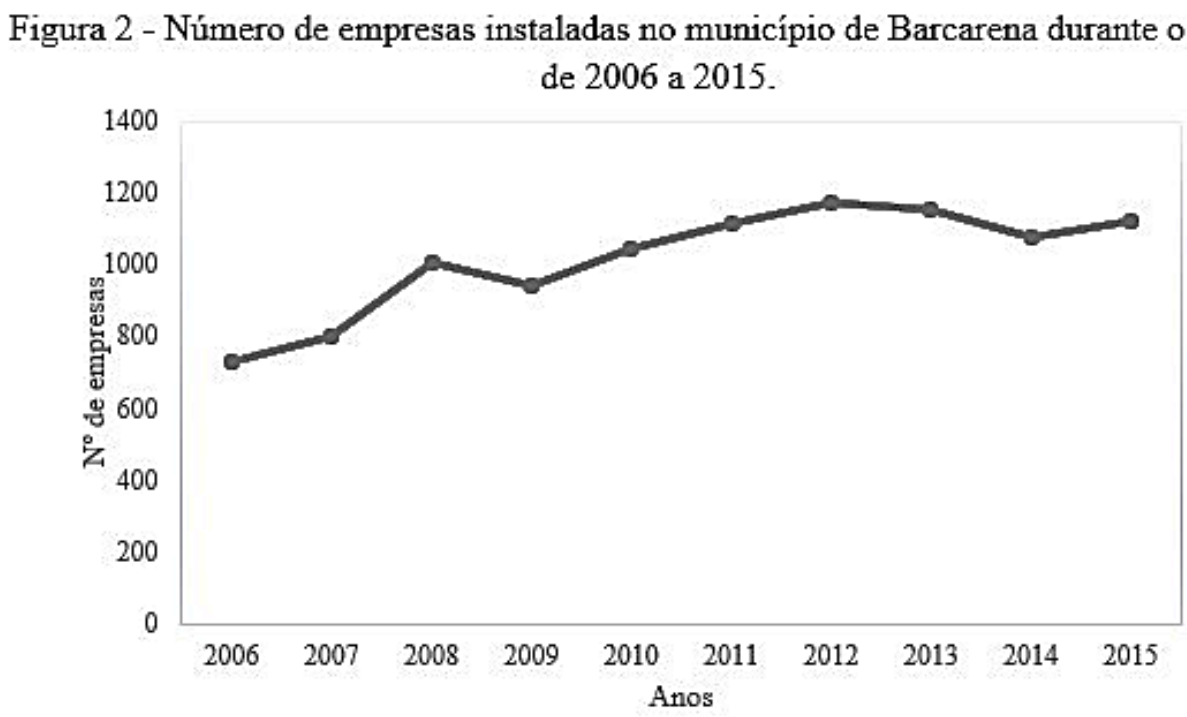

Fonte: autores (2018).

Esse acréscimo do número de empresas instaladas no município pode ser explicado pela vinda da empresa Albrás - Alumínio Brasileiro S.A, ainda no ano de 1985, que atraiu empresas devido ao desenvolvimento da economia local voltada principalmente para a extração de minérios. A inserção desses empreendimentos contribuiu de forma significativa para o Produto Interno Bruto - PIB, do município, obtendo um aumento de 85,21\% do ano de 2006 a 2015.

Algumas dessas empresas que contribuíram para Barcarena se transformar em um município industrial, foram a Alumínio Brasileiro S.A - Alumina Norte Brasil S/A Alunorte, principal empresa do setor de alumina; Pará Pigmentos - PPSA; Imerys Rio Capim Caulim - IRCC. Entretanto, pesquisa realizada em Belém - PA, por Barros (2009), afirma que no entorno dessas grandes empresas, existe mais de uma centena de outras 
prestadoras de serviços e fornecedoras de insumos o que fez a atividade industrial passar a responder por 70,59\% da economia local, provocando também acentuado êxodo rural.

Além de que, as inserções dessas empresas ocasionaram um intenso crescimento populacional, pelo fato de esses projetos desenvolvimentistas disporem de atrativos, os quais, ocasionam problemas socioambientais, interferindo diretamente na relação entre as populações e os recursos naturais existentes na região (BORDALO; SILVA; SANTOS, 2012).

Esses autores ainda relatam que devido à alguns impactos ocasionados por interferências antrópicas no Rio Murucupi, a população ficou impossibilitada de continuar a fazer uso da água do rio para atividades domésticas e balneabilidade. Esses fatos corroboram com a descrição feita por Ferreira (2015) sobre o incidente ocorrido no ano de 2009, no qual houve o derramamento de efluentes no rio Murucupi oriundos dos resíduos do processo de beneficiamento da bauxita (lama vermelha), o que promoveu alteração no corpo hídrico.

A restrição ao uso do recurso hídrico dar-se-á pelo atendimento à diretrizes legais da resolução CONAMA n.357:2005 que estabelece os limites aceitáveis desses parâmetros em águas superficiais tomando-se como referência águas Classe II, ou seja, aquelas utilizadas para consumo humano após tratamento convencional, à proteção das comunidades aquáticas, à recreação de contato primário, à irrigação e à aquicultura.

No entanto, dentre os objetivos da PNRH, ressalta-se que "a bacia hidrográfica é a unidade territorial para implementação da Política Nacional de Recursos Hídricos e atuação do Sistema Nacional de Gerenciamento de Recursos Hídricos". Os dados documentais indicaram que não houve a efetivação de um monitoramento da bacia do rio Mucurupi devido à ausência de articulação entre as entidades competentes governamentais, no que concerne à PNRH, art. $1^{\circ}$, inciso VI, "a gestão dos recursos hídricos deve ser descentralizada e contar com a participação do Poder Público, dos usuários e das comunidades".

No que tange às funções principais do solo, a resolução CONAMA n.420:2009, preconiza no art. $3^{\circ}$, dos incisos I ao VIII, a interdependência que há entre a manutenção do solo e da água. Porém, o lançamento dos rejeitos no solo atinge a qualidade do mesmo ao expô-lo a substâncias químicas, o que indica a importância de fiscalizações no município, levando em consideração o tipo de economia pautada na extração de minérios (beneficiamento da bauxita) processo no qual contém resíduos químicos prejudiciais à tanto à saúde humana, quanto das comunidades bióticas da área afetada.

\section{CONSIDERAÇÕES FINAIS}

As interferências antrópicas no meio natural visam o desenvolvimento econômico e local, porém desequilibram a manutenção da qualidade dos ecossistemas. $\mathrm{O}$ rio Murucupi, situado no município de Barcarena - PA, devido à sua localidade tornou-se alvo das principais descargas de efluentes advindos dos rejeitos produzidos a partir do beneficiamento da bauxita. A inserção das indústrias de alumina desencadearam impactos 
socioambientais no rio e no seu entorno, apesar de que a implementação desses empreendimentos contribuiu para o aumento de $85,21 \%$ no PIB do município, o que alterou o panorama socioeconômico. No entanto, quanto aos impactos ambientais, há a deterioração dos componentes físico-químicos e biológicos do corpo hídrico por meio dessas descargas de rejeitos químicos, que ocasionaram a perda da qualidade da água e restrição do uso desse recurso. Tais fatos, demonstram a vulnerabilidade dos recursos naturais e a fragilidade da gestão ambiental e hídrica dessas empresas. Bem como, a ausência de órgãos fiscalizadores estaduais e municipais responsáveis pelo cumprimento da Política Nacional dos Recursos Hídricos e das resoluções CONAMA n. 357:2005 e n. 420:2009.

\section{REFERÊNCIAS}

ANTUNES, M. L. P et al. Bauxita e seu resíduo, caracterização e estudo por microscopia eletrônica. In: CONGRESSO LATINO-AMERICANO DE CERÂMICA IX BRAZILIAN SYMPOSIUM ON GLASS AND RELATED MATERIALS. V.1, n. 2. 03 a 06 de junho de 2012, Curitiba, PR, Brasil.

ANTUNES, M. L. P.; CONCEIÇÃO, F. T.; NAVARRO, G. R. B. Caracterização da Lama Vermelha Brasileira (Resíduo do Refino da Bauxita) e Avaliação de Suas Propriedades Para Futuras Aplicações. In: INTERNATIONAL WORKSHOP

AUGUSTO, L. G. S. et al. O contexto global e nacional frente aos desafios do acesso adequado à água para consumo humano. Ciência e saúde coletiva. Rio de Janeiro, v. 17, n. 6, p. 1511-1522, 2012.

BAHIA, V. E. et al. Impactos ambientais no sistema hídrico superficial da Bahia do Marajó - localizada na área de abrangência do polo industrial de Barcarena (PA). In: CONGRESSO BRASILEIRO DE ÁGUAS SUBTERRÂNEAS, 17. 2012. São Paulo. Resumos... São Paulo: Revista águas subterrâneas, 2012. p. 1-4.

BARROS, M. J. B. Mineração, Finanças Públicas e Desenvolvimento Local no Município de Barcarena-Pará. 2009. 141f. Dissertação (Mestrado em Geografia). Universidade Federal do Estado do Pará, Belém, 2009.

BELTRAME, F, T.; LHAMBY, R. A.; BELTRAME, A. Efluentes, resíduos sólidos e educação ambiental: Uma DISCUSSÕES sobre o tema. Revista Eletrônica em Gestão, Educação e Tecnologia Ambiental. Santa Maria, v. 20, n. 01, p. .351-362, jan. /abr. 2016. DOI: $105902 / 2236117020052$.

BEM, C. C.; BRAGA, M. C. B.; AZEVEDO, J. C. R. de. Avaliação de um estado trófico de um lago urbano raso. REGA. v. 10, n. 01, p. 41-50, jan. /jun. 2013. Disponível em: < ttps://www.researchgate.net/profile/M_Braga/publication/307626053_Avaliacao_do_est ado_trofico_de_um_lago_urbano_raso/links/57f5572d08ae8da3ce552520/Avaliacaodo-estado-trofico-de-um-lago-urbano-raso.pdf>. Acesso em: 23 mai. 2018. 
BEZERRA, D. S.; MACHADO, K. A.; GOMES, A. C. Outorga de direito de uso da água e a política maranhense de recursos hídricos. Revista direito ambiental e sociedade. Caxias do Sul, v. 3, n. 2, p. 227-249, 2013.

BORDALO, C. A. L.; SILVA, F. A. O.; SANTOS, V. C. Por uma gestão dos recursos hídricos no estado do Pará: estudo de caso da bacia hidrográfica do rio Murucupi no município de Barcarena. Revista Geonorte. Amazonas, ed. Especial, v. 3, n. 4, p. 12161228, 2012.

BRASIL. Lei n. 9433, de 8 de janeiro de 1997. Institui a Política Nacional de Recursos Hídricos, cria o Sistema Nacional de Gerenciamento de Recursos Hídricos, regulamenta o inciso XIX do art. 21 da Constituição Federal, e altera o art. $1^{\circ}$ da Lei $n^{\circ} 8.001$, de 13 de março de 1990, que modificou a Lei no 7.990, de 28 de dezembro de 1989. Disponível em: < http://www.planalto.gov.br/ccivil_03/Leis/L9433.htm>. Acesso em: 22 mai. 2018.

Resolução Conama n. 357, de 17 de março de 2005. Dispõe sobre a classificação dos corpos de água e diretrizes ambientais para o seu enquadramento, bem como estabelece as condições e padrões de lançamento de efluentes, e dá outras providências. Brasília: MMA, 2005. Disponível em <http://www.mma.gov.br/port/conama/legiabre.cfm?codlegi=459>. Acesso em: 18 mar. 2018.

. Resolução Conama n. 420, de 30 de dezembro de 2009. Dispõe sobre critérios e valores orientadores de qualidade do solo quanto à presença de substâncias químicas e estabelece diretrizes para o gerenciamento ambiental de áreas contaminadas por essas substâncias em decorrência de atividades antrópicas. Brasília: MMA, 2009. Disponível em: < http://www.mma.gov.br/port/conama/res/res09/res42009.pdf>. Acesso em: 22 mai. 2018.

CARMO, M. B. S.; COSTA, S. M. F. Os paradoxos entre os urbanos no município de Barcarena, Pará. Revista brasileira de gestão urbana. Curitiba, v. 8, n. 3, p. 291-305, set. /dez. 2016.

COUCEIRO, S. R. M.; HAMADA, N. Os instrumentos da política nacional dos recursos hídricos na região norte do Brasil. Oecologia australis. Rio de Janeiro, v. 15, n. 4, p. 762774, dez. 2011.

CUNHA, D. G. F.; CALIJURI, M. C. Análise probabilística de ocorrência de incompatibilidade da qualidade da água com o enquadramento legal de sistemas aquáticos estudo de caso do rio Pariquera-Açu (SP). Eng. Sanit. Ambient. Rio de Janeiro, v. 15, n. 4, p. 337-346, out. /dez. 2010.

FERREIRA, D. L. N. Território e bacia hidrográfica: reflexões teóricas para um modelo de gestão dos recursos hídricos na Amazônia. In: SILVA, C. N.; SILVA, J. M. P.; CHAGAS, C. A. N. Geografia na Amazônia paraense: territórios e paisagens. Belém: GAPTA/UFPA, p. 59-85, 2015. 
FERREIRA, S. C. B; LIMA, F. M. R; LEÃO, L. Remoção de sulfato de efluentes industriais por precipitação. Eng. Sanit. Ambient. Rio de Janeiro, v.16 n.4, p. 361-368, out. /dez. 2011.

FORTUNA, J. et al. Processo Bayer de obtenção de alumina como ferramenta para o ensino de conceitos de estequiometria. In: ENCONTRO NACIONAL DE ENSINO DE QUIIMICA/X ENCONTRO DE EDUCAÇÃO QUIMICA DA BAHIA. 16. Bahia. Anais eletrônicos. $2013 . \quad$ Disponível em: https://portalseer.ufba.br/index.php/anaiseneq2012/article/view/7702/5643> . Acesso em; 10 mar.2018.

GIL, A. C. Métodos e técnicas de pesquisa social. São Paulo, Atlas. 6. ed., 2008.

IEC. Instituto Evandro Chagas. Relatório técnico SAMAM 001: caracterização dos impactos ambientais, danos ao ecossistema e riscos à saúde decorrentes do lançamento no rio Murucupi de efluentes do processo de beneficiamento de bauxita, Barcarena, Pará. Ananindeua: IEC; 2009.

PEREIRA, R. M. V.; MEDEIROS, R. A aplicação dos instrumentos de gestão e do sistema de gerenciamento dos recursos hídricos na lagoa Rodrigo de Freitas, RJ, Brasil. AmbiAgua. Taubaté, v. 4, n. 3, p. 211-229, 2009.

PRODANOV, C. C.; FREITAS, E. C.; Metodologia do Trabalho Científico: Métodos e Técnicas da Pesquisa e do Trabalho Acadêmico. 2 ed. Novo Hamburgo: Feevale, 2013.

SILVA, T. S. Direito fundamento de acesso a água potável. Idea Revista. Uberlândia, v. 7, n. 2, jul. /dez. 2016.

SOUZA, J. R. et al. A Importância da Qualidade da Água e os seus Múltiplos Usos: Caso Rio Almada, Sul da Bahia, Brasil. REDE - Revista Eletrônica do Prodema. Fortaleza, v.8, n.1, p. 26-45, abr. 2014.

WOLKMER, M. F. S.; PIMMEL, N. F. Política nacional de recursos hídricos: governança de água e cidadania ambiental. Revista Sequência. Florianópolis, v. 34, n. 67, p. 165-198, dez. 2013. 